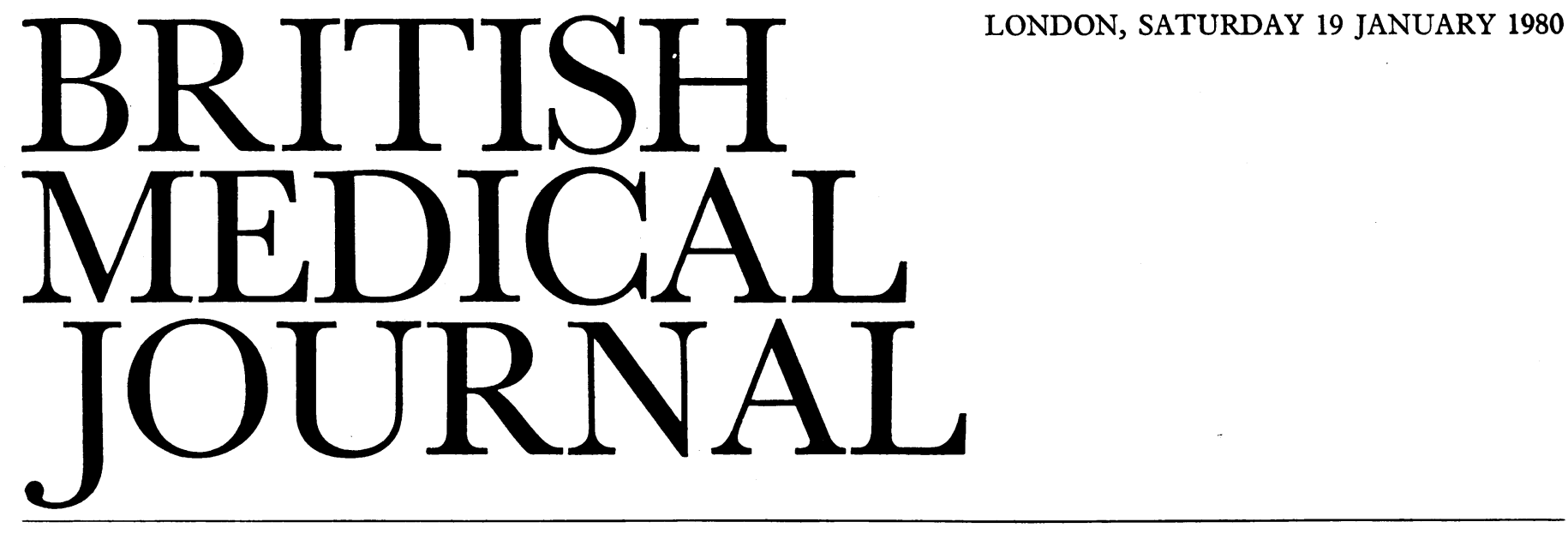

\title{
Drinking and driving: the leisurely approach
}

Drinking drivers cause some 1200 deaths a year-about one-fifth of all deaths on the road-and one-third of all drivers killed have a blood alcohol concentration over the legal limit, a proportion that rises to two-thirds at night. These figures, published in the Government's recent consultation document on drinking and driving, ${ }^{1}$ are much the same as those given in the Blennerhassett Report of $1976,{ }^{2}$ which was prompted by the failure of the Road Safety Act 1967 to maintain its dramatic impact on deaths and serious injuries related to drunken driving. The proposals made in the consultation document are largely based on the recommendations of the Blennerhassett Committee. Thus the most surprising feature of the present report is why it has taken so long.

The reforms now proposed (subject to public comment) are mainly welcome. The present offences of driving while impaired by drink and driving with an alcohol concentration above the prescribed limit would be merged into a single "impairment" offence, with an excess alcohol concentration as an "irrebuttable presumption of impairment." Procedural requirements would be reduced to a minimum in the new legislation and present loopholes would disappear-for example, arrest on the wrong grounds would not invalidate proceedings. The proposed use of breath testing as the normal method of providing evidence should greatly simplify matters. The proposal, however, that a suspect should have the initial option of providing a blood sample but could not ask for blood analysis once the breath alcohol concentration was found to be over the limit comes as a surprise. It runs counter to the Blennerhassett Report's recommendation, and indeed to the system successfully operated in Northern Ireland for the last 12 years. $^{3}$ The Government's argument is that once the legal limit is specified, as it proposes, in terms of breath (40 $\mu \mathrm{g}$ alcohol $/ 100 \mathrm{ml}$ breath) as well as blood alcohol an acceptable blood concentration would be no defence against an unacceptable breath concentration. But this view takes too little account of the variability in the operating conditions of breath testing or of the physiological variability among individuals, ${ }^{4}$ which could lead to both unwarranted convictions and unwarranted acquittals. In Northern Ireland the law is still framed in terms of blood concentration alone; and after the breath concentration has been found to exceed the legal limit there is the option of asking for blood analysis, a valuable safeguard in borderline cases. More discussion and more study of the scientific evidence are essential before final proposals appear.
The Government has not reached a conclusion on the procedure for high-risk offenders or on the extent to which the police should have the power to carry out breath testing, and it particularly wishes to have comments on these aspects. For second offenders and those with a very high alcohol concentration (representing at least 11 double whiskies) the report favours a modified version of the Blennerhassett Committee's proposal: disqualification for at least three years (as now) rather than one year, with a special order requiring evidence that the offender no longer presents an undue risk before his licence is restored (the latter possibly on an experimental basis to start with). Here the difficulties are mainly practical: what services would be provided for these heavy drinkers (some 15000 a year) to help them overcome their problem, and what kind of evidence of cure should the courts demand ? It would be tragic if the undoubted difficulties led to a watered-down or ineffective version of this measure, for problem drinkers contribute disproportionately to alcohol-related accidents. ${ }^{5}$ Doctors in particular should respond to the Government's request for suggestions.

How far the police should breath test is a more contentious issue. The Government is opposed to "indiscriminate" testing and is uncertain whether the present restrictions can be removed without making it so. The argument for removing them, as the report concedes, is that they undermine the lawat present the risk of detection is minute and hence the 1967 legislation has lost its force. ${ }^{5}$ Truly random breath testing is anyway not feasible-there are not enough policemen, and at most times of day and in most locations it would be a waste of time; moreover, the police are anxious about their relations with the public. But discretion to do breath tests in circumstances where drunk drivers are often found-such as near pubs at closing time-is surely a different matter. Those with little or no alcohol in their breath would have nothing to worry about and should not resent such a small intrusion in the interest of safer roads. Some other countries, such as Sweden, have much more extensive breath testing; is Britain over squeamish about interfering with personal liberty where matters of life and death are concerned? Certainly-as the present report and many others emphasise-we need more education, especially for young drivers (in $197646 \%$ of those in their twenties and thirties who were killed had drunk beyond the legal $\operatorname{limit}^{6}$ ). But even well-informed and responsible people continue to drive after drinking, and until we have a radical change in social attitudes ${ }^{7}$ there will be no substitute for a law that is enforced and seen to be enforced. 
The Government clearly means business, but how many more thousands of deaths - and tens of thousands of injuriesmust occur unnecessarily before a White Paper is published, new legislation is drafted, and time is found for it in the Parliamentary timetable? We hope that doctors who see the havoc caused by drunk drivers will make their views known both on the content and on the urgency of legislation.

${ }^{1}$ Department of Transport. Consultative document on drinking and driving. London: Department of Transport, 1979.

2 Department of the Environment. Drinking and driving. Report of the departmental committee. (Blennerhassett Report.) London: HMSO, 1976.

${ }^{3}$ Department of the Environment. Drinking and driving in Northern Ireland. Belfast: Department of the Environment, 1979.

4 Wright BM. Breath, alcohol, and the law. Br Med f 1977;i:1216-7.

5 Havard JDJ. Alcohol and the driver. Br Med f 1978; ; :1595-7.

6 Sabey BE. A review of drinking and drug-taking in road accidents in Great Britain. TRRL Supplementary Report 441. Crowthorne: Transport and Road Research Laboratory, 1978.

${ }^{7}$ Anonymous. Drinking and driving accidents-does education help? Br Med F 1978;ii:1352-4.

\section{Perioral dermatitis}

The fact that strong topical steroids can change trivial dermatoses of the face into a recognisable entity, perioral dermatitis; has been known since $1972 .^{12}$ The eruption is a persistent erythema composed of papules and papulopustules which extends around the mouth, sparing a narrow zone close to the vermilion border of the lips. In severe examples the cheeks, eyelids, and glabella (the region between the eyebrows) may be affected. Treatment is not easy, since any attempt to discontinue the topical steroid or substitute one of lower potency results in a rebound exacerbation of the eruption. This tempts the patient to resume applications of the strong steroid to obtain relief and so continues the vicious circle.

Wilkinson et $a l^{3}$ have recently reviewed 203 patients seen in the last 12 years, confirming the findings of others that perioral dermatitis is predominantly a disorder of young women. ${ }^{14}$ Of their 203 patients, 173 were women, 15 were men, and 15 children under 12 . The average age of patients with rosacea, with which perioral dermatitis may be confused, is considerably older. Wilkinson et $a l^{3}$ tested some of the theories that have been put forward to explain the disorder, but they found no pathogenic organisms or Demodex folliculorum; patch tests showed no evidence of contact sensitivity to cosmetics; and hormonal factors, including the use of oral contraceptives, showed no correlation with the eruption. Another recent theory, ${ }^{5}$ that fluorinated toothpaste might be the cause, was excluded, since patients recovered while still using it. The final conclusion-as might be expected-was that, since all but nine patients had admitted the use of topical corticosteroids, misuse of these preparations offered the most satisfactory explanation for the onset of the eruption. Further support for this theory comes from the rise in the number of cases of perioral dermatitis in 1966-70, when corticosteroids were used extensively on the face, and the fall as the knowledge of their possible aetiological role spread at first to the medical profession and later, via the press, to the public.

Yet, despite all the publicity, Cotterill saw 43 patients with perioral dermatitis between 1974 and $1978 .^{\circ}$ All his patients had used topical steroid preparations on the face, but 15 of them had obtained the drugs without consulting a doctor. The usual source of supply was a tube of ointment prescribed for another member of the family. Cotterill made another important point. Seven patients had used hydrocortisone butyrate, a non-fluorinated steroid, which does not interfere with the beneficial effect of tetracycline in perioral dermatitis. ${ }^{7}$ He listed other relatively weak steroids, including clobetasol butyrate, which he also blamed.

The conclusion must be that any steroid preparation stronger than $1 \%$ hydrocortisone may cause perioral dermatitis when applied to the face. Since self-medication is so common, Cotterill has suggested that tubes of steroid cream should carry a warning notice about their use on the face, and this proposal deserves serious attention from the manufacturers. Once diagnosed, the treatment of perioral dermatitis is simple. Almost always the condition can be resolved by a course of oral oxytetracycline $250 \mathrm{mg}$ twice daily at least 45 minutes before a meal for four weeks, followed by another month's treatment with one tablet daily, and the withdrawal of all topical steroids as soon as possible. Patients should be warned that an uncomfortable flare-up is to be expected but that this usually subsides in two weeks. One final comment: powerful topical steroids are sometimes indicated in the treatment of some skin disorders of the face; but well-informed patients may question this form of treatment, and their doubts warrant a detailed explanation.

1 Sneddon I. Perioral dermatitis. Br $\mathcal{f}$ Dermatol 1972;87:430-4.

2 Weber G. Rosacea-like dermatitis: contraindication or intolerance reaction to strong steroids. Br f Dermatol $1972 ; 86: 253-9$.

3 Wilkinson DS, Kirton V, Wilkinson JD. Perioral dermatitis: a 12-year review. Br f Dermatol 1979;101:245-57.

${ }^{4}$ Hjorth N, Osmundsen P, Rook AJ, Wilkinson DS, Marks R. Perioral dermatitis. Br F Dermatol 1968;80:307-13.

${ }^{5}$ Melletle JR, Aeling JL, Nuss DD. Fluoride tooth paste: a cause of perioral dermatitis. Arch Dermatol 1976;112:730-1.

6 Cotterill JA. Perioral dermatitis. Br f Dermatol 1979;101:259-62.

7 Sneddon I. A trial of hydrocortisone butyrate in the treatment of rosacea and perioral dermatitis. Br $\mathcal{F}$ Dermatol 1973;89:505-8.

\section{The uneasy oesophagus}

"Your chest pain is due to cramp in the gullet," says the physician out to reassure his worried patient who believes that he has heart disease. How often, however, do symptoms really originate in the oesophageal muscle? Barium swallow radiographs can certainly show non-propulsive ("tertiary") contractions in many people on occasions. These are highpressure squeezes which are not co-ordinated as part of a progressive peristaltic wave; they become more common with advancing years, and the condition has been called presbyoesophagus. The normal motility of the oesophagus may eventually become disorganised, with diminished peristalsis and dilatation of the lumen; the cause is thought to be muscular atrophy rather than autonomic neuropathy. ${ }^{1}$

The difficulty of classifying disorders of oesophageal motility stems from the considerable overlap in signs and symptoms-and, to complicate matters further, spasm may occur with any lesion causing oesophageal obstruction or oesophagitis. The best-known neuromuscular motor disorder is achalasia of the cardia. ${ }^{2}$ Damage to the myenteric plexus of the entire oesophagus causes loss of the normal peristaltic wave and failure of the lower oesophageal sphincter to relax. Away from South America-where the picture is complicated by a type of achalasia due to Chagas's disease-the annual incidence is about 1 in $100000 .{ }^{4}$ Dysphagia is the cardinal symptom, but the clinical picture is eventually completed by the effects of progressive dilatation of the oesophagus with 